\title{
A VIOLÊNCIA SIMBÓLICA NA ESCOLA: CONTRIBUIÇÕES DE SOCIÓLOGOS FRANCESES AO FENÔMENO DA VIOLÊNCIA ESCOLAR BRASILEIRA
}

\section{SIMBOLIC VIOLENCE IN SCHOOL: FRENCH SOCIOLOGISTS CONTRIBUTIONS TO THE PHENOMENON OF BRAZILIAN SCHOOL VIOLENCE}

\author{
Liliane Pereira de Souza ${ }^{1}$
}

\section{RESUMO}

Este artigo aborda o fenômeno histórico e atual da violência escolar, que a partir da década de 1980, no Brasil, vem sendo discutido e adquirindo grande importância para pesquisadores de diversas áreas. Nele a violência considerada não é a do ato praticado no sentido de agressão física, mas a violência simbólica, conceito criado pelo sociólogo francês Pierre Bourdieu, segundo o qual a ação pedagógica é objetivamente estruturada e impõe um arbitrário cultural de um grupo de classe a outro grupo de classe. Analisando o fenômeno da violência simbólica é possível identificar sua presença no contexto histórico escolar brasileiro.

Palavras-chave: Escola - Violência simbólica - Estado

\section{ABSTRACT}

This article discusses the current and historical phenomenon of school violence, which since the 1980s, Brazil has been discussed and acquiring great importance to researchers in several areas. In it is considered non violence of the act committed in the sense of physical aggression, but thesymbolic violence, a concept created by the French sociologist Pierre Bourdieu, in wich the action is objectively structured teaching and imposesan arbitrary one cultural group to another class class group. Analyzing in phenomenon of symbolic violence is possible to identify its presence in the Brazilian school historical context.

Keywords: School - Symbolic violence - State

\section{INTRODUÇÃO}

Neste artigo apresenta-se uma reflexão sobre a violência simbólica presente nas escolas. Trata de um fenônemo histórico e atual, como podemos observar nas referências dos autores como Pierre Bourdieu, Émile Durkheim, Bernard Charlot, Marilia Pontes Sposito, Miriam Abramovay dentre outros que contribuem para o melhor entendimento desta violência que devido à problematização do aumento da mesma e suas consequências para toda a 
sociedade, vem sendo discutida e adquirindo grande importância para pesquisadores de diversas áreas.

O objetivo é identificar o fenômeno da violência simbólica na realidade do contexto escolar brasileiro. Na perspectiva Bourdieusiana, a violência simbólica se expressa na imposição legítima e dissimulada, com a interiorização da cultura dominante e há uma correlação entre as desigualdades sociais e escolares. As posições mais elevadas e prestigiadas dentro do sistema de ensino (definidas em termos de disciplinas, cursos, ramos do ensino, estabelecimentos) tendem a ser ocupadas pelos indivíduos pertencentes aos grupos socialmente dominantes.

Por mais que se democratize o acesso ao ensino por meio da escola pública e gratuita, continuará existindo uma forte correlação entre as desigualdades sociais, sobretudo culturais. Essa correlação só pode ser explicada quando se considera que a escola valoriza e exige dos alunos determinadas qualidades que são desigualmente distribuídas entre as classes sociais, notadamente, o capital cultural e certa naturalidade no trato com a cultura e o saber, que apenas aqueles que foram desde a infância socializados na cultura legítima podem ter.

\section{O FENÔMENO SOCIAL DA VIOLÊNCIA}

Segundo alguns autores a violência é algo complexo e polissêmico, isso é, apresenta diferentes sentidos, e o seu significado se define a partir do seu contexto formador social, econômico e cultural, de acordo com o sistema de valores adotados por cada sociedade e levando em considerações os seus níveis de tolerância para com a violência (SANTOS, 1999).

No entendimento de Oliveira e Martins (2007), a violência contra o ser humano faz parte de uma trama antiga e complexa: antiga, porque data de séculos as várias formas de violência perpetradas pelo homem e no próprio homem; complexa por tratar-se de um fenômeno intrincado, multifacetado. Podemos então considerar a violência como todo ato ao qual se aplique uma dose de força excessiva e a agressão como uma forma de violência (força contra alguém aplicada de maneira intencional, com a pretensão de causar um dano à outra pessoa).

A desigualdade social é apontada como uma das origens estruturais da violência e suscita nas sociedades contemporâneas. A contradição de uma 
sociedade desigual contribui para manifestações da violência física e moral. Favorece impulsos que se expressam através de hábitos, costumes, tradições.

Charlot (2002) evidencia que a violência enfatiza o uso da força, do poder, da dominação, que de certo modo toda agressão é violência na medida em que usa

a força. É a violência enquanto vontade de destruir, de aviltar, de atormentar, que causa problema. Todavia, a violência será bem mais provável na medida em que a palavra se torna impossível.

Santos (2004) ressalta que as diferentes formas de violência presentes em cada um dos conjuntos relacionais que estruturam o social podem ser explicadas se compreendermos a violência como um ato de excesso, qualitativamente distinto, que se verifica no exercício de cada relação de poder presente nas relações sociais de produção do social.

Ainda para o autor (2002), a matriz teórica vem sendo composta a partir de uma abordagem geral que se nutre dos clássicos do pensamento sociológico. Em Durkheim, as contribuições sobre a divisão social do trabalho, a relação entre norma e conflito, o conceito de anomia, dificultam o bom funcionamento da sociedade. Mais recentemente, as interpretações de Pierre Bourdieu sobre a violência simbólica tiveram relevo para explicar os "sentimentos de insegurança" nos fenômenos de violência.

\section{AS PRIMEIRAS PESQUISAS SOBRE A VIOLÊNCIA ESCOLAR}

A história demonstra que a violência nas escolas não é um fenômeno novo. Contudo, novas formas de violência escolar nascem cotidianamente, fatos estes que têm tornado a violência o objeto de estudo de pesquisadores de diversas áreas, pois ela afeta a sociedade como um todo.

Conforme relata Sposito (2001), a partir de 1980 ocorrem às primeiras pesquisas sobre violência escolar no Brasil, quando o tom predominante era de expor as constantes depredações e atos de vandalismo. Constata-se que a partir dos anos 1990, a violência escolar passa a ser preponderante nas interações dos grupos de alunos, aumentando a complexidade de análise destes fenômenos. Neste sentido, é possível evidenciar, por exemplo, a frequente existência de agressões verbais e ameaças. 
Também na década de 1990, na Europa, Charlot em seu estudo sobre a abordagem da violência na escola por sociólogos franceses ensejou a multidiversificação do fenômeno da violência e, além disso, a importância de preliminarmente distingui-lo perante as diversificações existentes:

\begin{abstract}
A violência na escola é aquela que se produz dentro do espaço escolar, sem estar ligada à natureza e às atividades da instituição escolar: quando um bando entra na escola para acertar contas das disputas que são as do bairro, a escola é apenas o lugar de uma violência que teria podido acontecer em qualquer outro lugar.

A violência à escola está ligada à natureza e às atividades da instituição escolar: quando os alunos provocam incêndios, batem nos professores ou os insultam, eles se entregam a violências que visam diretamente a instituição e aqueles que a representam. Essa violência contra a escola deve ser analisada junto com a violência da escola: uma violência institucional, simbólica, que os próprios jovens suportam através da maneira como a instituição e seus agentes os tratam (modos de composição das classes, de atribuição de notas, de orientação, palavras desdenhosas dos adultos, atos considerados pelos alunos como injustos ou racistas...) (CHARLOT, 2002, p. 434 e 435).
\end{abstract}

Considerando a natureza do fenômeno, é importante destacar que não somente $O$ ato da violência entre alunos deve ser exposto, mas também a capacidade da escola enquanto instituição e de seus gestores de suportar e criar situações de conflito, ligadas à cultura da própria escola, sem que essas situações não esmaguem os alunos sob o peso da violência institucional e simbólica. Em Julia (2001) é possível encontrar uma breve descrição sobre a cultura escolar:

\begin{abstract}
Como um conjunto de normas que definem conhecimentos a ensinar e condutas a inculcar, e um conjunto de práticas que permitem a transmissão desses conhecimentos e a incorporação desses comportamentos; normas e práticas coordenadas a finalidades que podem variar segundo as épocas [...] Normas e práticas não podem ser analisadas sem se levar em conta o corpo profissional dos agentes que são chamados a obedecer a essas ordens e, portanto, a utilizar dispositivos pedagógicos encarregados de facilitar sua aplicação, a saber, os professores primários e os demais professores (2001, p. 10).
\end{abstract}

Para Bourdieu e Passeron até em suas omissões, a ação escolar do tipo tradicional "serve automaticamente os interesses pedagógicos das classes que necessitam da Escola para legitimar escolarmente o monopólio de uma relação com a cultura que elas não the devem jamais completamente" (BOURDIEU E PASSERON, 1992, p. 140). 
A violência simbólica parte do princípio de que a cultura simbólica ou sistema simbólico é arbitrário, uma vez que não assenta numa realidade dada como natural, o sistema simbólico de uma determinada cultura é uma concessão social, e sua manutenção é fundamental para a perpetuação de uma determinada sociedade, através de interiorização da cultura por todos os membros da mesma.

\section{CONCEITOS DE HABITUS E CAMPO}

O conceito de habitus é a mais conhecida das idéias de Bourdieu. O conceito tem uma longa história (Aristóteles, Boetius, Averroes, Tomás de Aquino, Hegel, Mauss, Husserl, Heidegger, Merleau-Ponty...). A definição adotada por Bourdieu foi pensada como um expediente para escapar do paradigma objetivista do estruturalismo sem recair na filosofia do sujeito e da consciência. Aproxima-se da noção de Heidegger do modo-de-ser no mundo, mas tem características próprias. "Para Bourdieu, o habitus é um sistema de disposições, modos de perceber, de sentir, de fazer, de pensar, que nos levam a agir de determinada forma em uma circunstância dada" (THIRY-CHERQUES, 2006, p. 32).

Bourdieu evidencia que:

É a sua posição presente e passada na estrutura social que os indivíduos, entendidos como pessoas fisicas, transportam com eles, em todo tempo e lugar, sob forma de habitus. Os indivíduos "vestem" os habitus como hábitos, assim como o hábito faz o monge, isto é, faz a pessoa social, com todas as disposições que são, ao mesmo tempo, marcas da posição social e, portanto, da distância social entre as posições objetivas, entre as pessoas sociais conjunturalmente aproximadas e a reafirmação dessa distância e das condutas exigidas para "guardar suas distâncias" ou para manipulá-las estratégica, simbólica ou realmente reduzí-las, aumentá-las ou simplesmente mantê-las (1983, p. 75).

Habitus surge como uma definição para conciliar a oposição aparente entre realidade exterior e as realidades individuais. Para Bourdieu, habitus são determinados pela condição de classe e se refere tanto a uma classe quanto a um grupo.

Para Bourdieu e Passeron consideraram que:

Se, no caso particular das relações entre a Escola e as classes sociais, a harmonia parece perfeita, é que as estruturas objetivas produzem os habitus de classe, e em particular as disposições e as predisposições que, 
gerando as práticas adaptadas a essas estruturas, permitem 0 funcionamento e a perpetuação dessas estruturas (1992, p. 213).

Ainda, mostram que o sistema de ensino dentro da sociedade capitalista tem uma dupla função: a reprodução da cultura e a reprodução da estrutura de classes. Quando integra do conceito de habitus, Bourdieu toma as idéias da luta pela dominação e da consciência de classe do marxismo.

Quanto ao conceito de campo, para Bourdieu:

Se particulariza, pois, como um espaço onde se manifestam relações de poder, o que implica afirmar que ele se estrutura a partir da distribuição desigual de um quantum social que determina a posição que um agente específico ocupa em seu seio. Bourdieu denomina quantum de capital social (BOURDIEU, 1983, p. 21).

Segundo Thiry-Cherques (2006), o sistema de ensino é visto por Bourdieu como empreendimento da cultura de classes. O autor sustentou que a cultura escolar, dominada pela cultura burguesa através dos códigos comportamentais, lingüísticos e intelectuais, reproduz as ilusões (illusio) necessárias ao funcionamento e à manutenção do sistema: as crenças compartilhadas em um campo. Sendo que, a família, a escola, o meio não só reproduzem as desigualdades sociais, como legitimam inconscientemente esta reprodução. São aparelhos de dominação. A desigualdade não residindo no acesso ao campo, mas no âmago do próprio sistema.

O campo é delimitado pelos valores ou formas de capital que lhe dão sustentação; a dinâmica social no interior de cada campo é regido pelas lutas em que os agentes procuram manter ou alterar as relações de força e a distribuição das formas de capital específico.

Segundo Bourdieu e Passeron (1992), o habitus adquirido na família esteja no princípio da recepção e da assimilação da mensagem escolar, e que "o hábito adquirido na escola esteja no princípio do nível de recepção e do grau de assimilação das mensagens produzidas e difundidas pela indústria cultural" (BOURDIEU E PASSERON, 1992, p. 54). De acordo com Adorno (1995), a indústria cultural é um instrumento de manipulação das consciências, usada pelo sistema para se conservar, se manter ou submeter os indivíduos. 


\section{A ESCOLA E A VIOLÊNCIA SIMBÓLICA}

Para entender melhor as relações entre as práticas da violência e a escola, é necessário saber que esta se passa pela reconstrução das relações sociais que estão presentes no espaço social escolar.

Para Oliveira e Martins (2007):

A violência que se configura dentro do espaço escolar, manifestada através do comportamento dos alunos, lança professores diante da confusão da possibilidade de um ensino libertador (caso seja esta a sua proposta) e de uma realidade insuportável, na qual os educadores recorrem a expedientes autoritários e até mesmo violentadores, a fim de manter a "ordem geral". São estabelecidas regras, controles, punições e dominações para disciplinar os alunos em estados de rebeldia (OLIVEIRA E MARTINS, 2007, p. 95).

É neste escopo que emergem os conflitos e as crises dentro da escola, que podemos perceber melhor o seu funcionamento atribuído à sua finalidade. Em $A$ Reprodução, Bourdieu e Passeron tratam da questão da escola e, segundo os autores, toda ação pedagógica é objetivamente uma violência simbólica enquanto imposição, por um poderªrbitrário, de um arbitrário cultural. Segundo os autores: "A ação pedagógica inicial deriva seu principal recurso, sobretudo quando tenciona desenvolver a sensibilidade a uma forma particular de capital simbólico ${ }^{3}$, dessa relação originária de dependência simbólica" (BOURDIEU E PASSERON, 2001, p. 202).

Esse poder de violência simbólica só exerce sua função pedagógica "quando são dadas as condições sociais de imposição e inculcação" (BOURDIEU, 1975, p.22).

Como afirma Stoer (2008):

A ação pedagógica reproduz o arbitrário cultural das classes dominantes ou dominadas. A ação pedagógica (institucionalizada) da escola reproduz a cultura dominante e, através desta, a estrutura de relações de força dentro de uma formação social, possuindo o sistema educativo dominante o monopólio da violência simbólica legítima. Todas as ações pedagógicas praticadas por diferentes classes ou grupos sociais apoiam objetiva e indiretamente a ação pedagógica dominante, porque esta última define a estrutura e o funcionamento do mercado econômico e simbólico (2008, p. 15).

O poder arbitrário na escola é responsável pela imposição e inculcação, que são as relações de força, do arbitrário cultural, pois os conteúdos, métodos de 
trabalho, avaliação, são impostos pelos agentes como importantes e merecedores de serem ensinados. Sendo assim, através da ação pedagógica, mantêm-se a reprodução, de uma violência simbólica. E defende Bourdieu e Passeron que a condição da prática da ação pedagógica é o não reconhecimento.

Para Adorno (1995):

A imagem do professor sendo aquele que é fisicamente mais forte e que castiga o mais fraco também afeta a vantagem do saber do professor frente ao saber de seus alunos, que ele utiliza sem ter direito para tanto, uma vez que a vantagem é indissociável de sua função, ao mesmo tempo em que sempre lhe confere uma autoridade de que dificilmente consegue abrir mão (1995, p. 104).

O dominado não se opõe ao seu opressor, já que não se percebe como vítima deste processo, ao contrário, o oprimido considera a situação natural e inevitável. Nas escolas públicas brasileiras, ignoram-se a origem dos seus alunos, transmitindo o ensino padrão. Bourdie e Passeron explicam este processo pela Ação Pedagógica, que perpetua a violência simbólica através de duas dimensões arbitrárias: o conteúdo da mensagem transmitida e o poder que instaura a relação pedagógica exercido por autoritarismo.

Segundo Durkheim exige-se na prática que o professor tenha autoridade (1972):

\begin{abstract}
A educação deve ser um trabalho de autoridade. Para aprender a conter o egoísmo natural, subordiná-lo a fins mais altos, submeter os desejos ao império da vontade, conformá-los em justos limites, será preciso que o educando exerça sobre si mesmo um grande trabalho de contenção. Ora, não nos constrangemos e não nos submetemos senão por uma destas razões: ou por força da necessidade física, ou porque o devamos moralmente. Isso significa que a autoridade moral é a qualidade essencial do educador (DURKHEIM, 1972, p. 53-54).
\end{abstract}

Os agentes que exercem ação pedagógica são investidos de uma autoridade que vem das classes dominantes. Sobre os dominados, Bourdieu (2001) aponta que estes contribuem com frequência à sua revelia, outras vezes contra sua vontade, para sua própria dominação, aceitando tacitamente, como que por antecipação, os limites impostos:

Tal reconhecimento prático assume, muitas vezes, a forma da emoção corporal (vergonha, timidez, ansiedade, culpabilidade), em geral associada à impressão de uma regressão a relações arcaicas, aquelas características da infância e do universo familiar. Tal emoção se revela por manifestações visíveis, como enrubescer, o embaraço verbal, o desajeitamento, o tremor, 
diversas maneiras de se submeter, mesmo contra a vontade e a contragosto, ao juízo dominante, ou de sentir, por vezes em pleno conflito interior e na "fratura do eu", a cumplicidade subterrânea mantida entre um corpo capaz de desguiar das diretrizes da consciência e da vontade e a violência das censuras inerentes às estruturas sociais (BOURDIEU, 2001, p. 205).

A violência simbólica é essa coerção que se institui por intermédio da adesão que o dominado não pode deixar de conceder ao dominante (portanto, à dominação), quando dispõe apenas, para pensá-lo e para pensar a si mesmo, ou melhor, para pensar sua relação com ele, de instrumentos de conhecimento partilhados entre si e que fazem surgir essa relação como natural, "pelo fato de serem, na verdade, a forma incorporada da estrutura da relação de dominação" (BOURDIEU, 2001, p. 206).

Abramovay (2002) acrescenta ainda que são manifestações de violência simbólica: abuso do poder, baseado no consentimento que se estabelece e se impõe mediante ouso de símbolos de autoridade; verbal; e institucional como a marginalização, discriminação e práticas de assujeitamento utilizadas por instituições diversas que instrumentalizam estratégias de poder.

Esta violência se mostra nas relações de poder, na violência verbal entre professores e alunos, na discriminação indireta de gêneros e raça, entre outras e descreve o processo pelo qual a classe que domina economicamente impõe sua cultura aos dominados.

Pode-se atribuir à escola brasileira a reflexão de Bourdieu, segundo a qual:

\footnotetext{
Se considerarmos seriamente as desigualdades socialmente condicionadas diante da escola e da cultura, somos obrigados a concluir que a eqüidade formal à qual obedece todo o sistema escolar é injusta de fato, e que, em toda sociedade onde se proclama ideais democráticos, ela protege melhor os privilégios do que a transmissão aberta dos privilégios (1998 p.53).
}

A realidade nas escolas brasileiras é o aumento significativo de alunos, a massificação do ensino num cenário onde o índice de pobreza da população é elevado e de poucos investimentos na área educacional. Acrescenta-se que a escola é vista como reprodutora das desigualdes sociais e que a exclusão é uma das grandes causas da violência na escola.

Abramovay (2002) ressaltou a realidade do cotidiano das escolas públicas brasileiras em exemplos de violência institucional, como alunos que relatam que há 
professores que têm dificuldade de dialogar com eles, humilhando-os e ignorando completamente seus problemas, não querendo nem sequer escutá-los. Outros tratam mal os alunos, recorrem a agressões verbais e os expõem ao ridículo quando estes não entendem algo ou quando não conseguem responder a uma pergunta.

A escola funciona como um aparelho ideológico de reprodução da ideologia da classe dominante. Segundo descreveu Bourdieu:

\begin{abstract}
A propensão das famílias, e das crianças para investir na educação, que constitui por si só um dos fatores importantes do êxito escolar depende do grau em que dependem dos sistemas de ensino para a reprodução de seu patrimônio e de sua posição social, bem como das oportunidades de seu sucesso prometidas a tais investimentos em função do volume de capital cultural que possuem (2001, p. 264).
\end{abstract}

O capital cultural designa nichos da atividade humana nos quais se desenrolam lutas pela detenção do poder simbólico que produz e confirma significados. Esses conflitos consagram valores que se tornam aceitáveis pelo senso comum. A posse de capital cultural favorece o desempenho escolar na medida em que facilita a aprendizagem dos conteúdos e códigos escolares.

Para os filhos das classes trabalhadoras, a escola representa uma ruptura no que refere aos valores e saberes de sua prática, que são desprezados, ignorados e desconstruídos na sua inserção cultural, ou seja, necessitam aprender novos padrões ou modelos de cultura. Sendo assim, para os alunos filhos das classes dominantes alcançarem o sucesso escolar torna-se bem mais fácil do que para aqueles que têm que desaprender uma cultura para aprender um novo jeito de pensar, falar, movimentar-se, enfim, enxergar o mundo, inserir neste processo para se tornar um sujeito ativo nesta sociedade.

\title{
O PAPEL DO ESTADO
}

O Estado influencia fortemente as relações de força. O caráter simbólico da violência centra-se nas características fundamentais da estrutura de classes da sociedade capitalista, decorrente da divisão social do trabalho e baseada na apropriação diferencial dos meios de produção. 
Formalmente, para o Estado, a escola trataria a todos de modo igual, todos assistiriam as mesmas aulas, seriam submetidos às mesmas formas de avaliação, obedeceriam às mesmas regras e, portanto, supostamente, teriam as mesmas chances. Todavia, as chances são desiguais, pois alguns estariam numa condição mais favorável do que outros para atenderem às exigências, muitas vezes, implícitas na escola.

A escola é um espaço de reprodução de estruturas sociais e de transferência de capitais. "A mais profunda e estrutural modalidade de violência perpetrada pelo Estado é a violência simbólica, cujo modus operandi se dá à sombra da permanente naturalização de seus objetos e/ou alvos, configurando o que se poderia chamar de um permanente "estado de violência", onde o que está em jogo não é a integridade física de indivíduos e/ou grupos, mas sim a integridade de sua participação cultural" (MENDONÇA, 1996, p. 2).

Durkheim (2002) defende a idéia que:

O indivíduo é produto da sociedade como um todo e sua existência só se torna real mediante a atuação do Estado. Entretanto, é somente com um equilíbrio de forças entre os grupos secundários e o Estado que o indivíduo pode existir de fato, afinal, "é desse conflito de forças sociais que nascem as liberdades individuais" (DURKHEIM, 2002, p. 88).

Para Bourdieu (2001), a instituição do Estado como detentor do monopólio da violência simbólica legítima atribui, por sua própria existência, um limite à luta simbólica de todos contra todos em torno desse monopólio, ou seja, pelo direito de impor seu próprio princípio de visão.

Neste sentido, o Estado como detentor do monopólio, coloca em dúvida a igualdade de oportunidades e a importância do sistema escolar para que isso aconteça. Sendo que na realidade brasileira, parte significativa da população encontra-se em situação de desemprego, abandono e inúmeras iniquidades características de um Estado agente de opressão e facilitador das realizações da classe dominante.

Segundo Bourdieu (1983):

As entidades metafísicas ("classe dominante" ou "aparelho de Estado") e as teorias puramente verbais, como as que fazem do Estado um aparelho onipotente ao serviço dos desígnios dos dominantes, cedem, desta maneira, o lugar a uma ciência rigorosa da concorrência pelo poder, em particular nas empresas ou nas administrações públicas, organismos 
capazes de concentrar e de redistribuir uma grande parte dos recursos disponíveis, graças ao poderes sobre os meios materiais (sobretudo financeiros), institucionais (regulamentação das relações sociais) e simbólicos, que são controlados pelas autoridades administrativas. Isto coloca uma interrogante sobre a parte que é deixada a ação propriamente política, ao governo, pelas leis tendências que a ciência social estabelece (BOURDIEU, 1983, p. 43).

Não é em grupos sociais ou nos indivíduos que se depara com o mecanismo da distribuição de oportunidades educacionais, mas na própria cultura acadêmica, e esta é ligada efetivamente a classe dominante.

A classe social não se define somente por uma posição nas relações de produção, mas pelo habitus de classe, que está normalmente associado a essa posição. O uso da violência simbólica é dirigido por um individuo, ou grupo, que controla o poder simbólico sobre os outros, fabricando crenças no processo de socialização, induzindo os dominados a enxergarem e a avaliarem o mundo de acordo com os critérios e padrões definidos pelos dominantes. Neste caso, como o Estado é facilitador das classes dominantes, suas ações para a melhoria ou não das condições das escolas públicas, em âmbito geral, vai depender dos interesses desta classe dominante.

\section{CONSIDERAÇÕES FINAIS}

A realidade educacional dentro de uma sociedade capitalista, esporadicamente, cumpre sua função como reprodutora de desigualdades sociais e culturais. Como parte do cotidiano escolar, a violência se torna fruto dessas desigualdades, quer seja através da imposição de regras coletivas ou pela repetição dos modelos que os alunos vivenciam no ambiente familiar.

No campo educacional, dada a sua natureza, a violência simbólica muitas vezes passa despercebida. Não obstante, em algumas situações, ela é claramente identificável. Quando as regras da escola não são claras, quando os alunos são préjulgados ou não são escutados, quando os professores afastam-se muitas vezes porque não conseguem responder aos anseios dos educandos ou, ainda, quando há a imposição de tarefas dobradas a estes, é exercida a violência simbólica.

Quando professores da rede pública brasileira percebem baixos salários e péssimas condições de trabalho, quando são forçados a adotar uma didática 
pré-definida e a abdicar a sua criatividade de educador, quando sofrem pela intransigência do Estado na resolução dos problemas educacionais e ensejam greves, materializam-se aí exemplos claros de violência simbólica. Afinal, a priori, o Estado mostra-se como detentor de poderes.

Desta maneira, percebe-se que, dentro da escola, a violência simbólica é sofrida multilateralmente, cotidianamente fazendo parte do processo educacional. Neste sentido, o primeiro passo para discuti-la demanda o estabelecimento de agentes e vítimas envolvidas neste fenômeno, o que causa preocupação de relevância e solidifica o comprometimento quanto à esse estudo.

Neste artigo, a escola é tomada como microcosmo da resolução dos problemas sociais, onde é possível identificar agentes, vítimas e o fenômeno da violência simbólica. Todavia, é importante salientar que a escola, como instituição social, mesmo preservando considerável parte da cultura do processo educacional e ao demonstrar-se como espelho dos problemas sociais, não encontrará exclusivamente em seu escopo a solução para a correção de todos os problemas.

A contribuição dos trabalhos realizados por Bourdieu e outros sociólogos no que concerne a educação é considerável, e tem grande valia para entendimento de que o fenômeno social não é unicamente produto das ações individuais, que a lógica dessas ações deve ser procurada na racionalidade dos agentes e sendo assim, que a instituição escola não é neutra. 


\section{REFERÊNCIAS}

ABRAMOVAY, Miriam et. all. Escola e violência. Brasília: UNESCO, 2002.

ADORNO, Theodor W. Educação e emancipação. Rio de Janeiro: Paz e Terra, 1995.

BOURDIEU, Pierre; PASSERON, Jean Claude. A reprodução: elementos para uma teoria do sistema de ensino. 3. ed., Rio de Janeiro: Francisco Alves, 1992.

A Reprodução. Elementos para uma teoria do sistema de ensino. Francisco Alves Editora S/A: Rio de Janeiro, 1975.

BOURDIEU, Pierre. Sociologia. São Paulo: Ática, 1983.

. O poder simbólico. 7. ed. Rio de Janeiro: Bertrand Brasil, 2004.

. Meditações Pascalianas. Rio de Janeiro: Bertrand Brasil, 2001.

- Escritos de educação. Organização: Maria Alice Nogueira e Afrânio Catani. Petrópolis, Vozes, 1998.

CHARLOT, B. A violência na escola: como os sociólogos franceses abordam essa questão. Sociologias, Porto Alegre, n.8, p. 432-443, 2002.

DURKHEIM, E. Educação e sociologia. São Paulo: Melhoramentos, 1972.

. Lições de sociologia: a moral, o direito e o Estado. São Paulo: Martins Fontes, 2002.

JULIA, Dominique. A cultura escolar como objeto historiográfico. Tradução: Gizele de Souza. Revista Brasileira de História da Educação, São Paulo, n. 1, 2001, p. 9-44. 
MENDONÇA, S. R. Estado, violência simbólica e metaforização da cidadania. Tempo, Rio de Janeiro, vol. 1, 1996, p. 94-125.

OLIVEIRA, É.C. S. e MARTINS, S. T. F. Violência, Sociedade e Escola: da recusa do diálogo à falência da palavra. Psicologia \& Sociedade, 19(1), p. 90-98; jan/abr, 2007.

SANTOS, José Vicente Tavares dos (Orgs.). A Palavra e o gesto emparedados: a violência na escola. PMPA, SMED. 1999.

SANTOS, José Vicente Tavares. Violências e dilemas do controle social nas sociedades da "modernidade tardia". São Paulo em Perspectiva, a. 18, n. 1, 2004.

- Violências, América Latina: a disseminação de formas de violência e os estudos sobre conflitualidades. Sociologias, Porto Alegre, ano 4, n" 8, jul/dez 2002, p. 16-32.

SPOSITO, M. Um breve balanço da pesquisa sobre violência escolar no Brasil. Educação e Pesquisa, São Paulo, v. 27, n.1, p. 87-103, 2001.

STOER, S. R. A genética cultural da reprodução. Educação, Sociedade \&

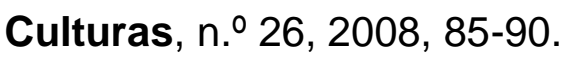

THIRY-CHERQUES, H.R. Pierre Bourdieu: a teoria na prática. Revista Administração Pública. 2006, vol.40, n.1, pp 27-53.

\footnotetext{
${ }^{1}$ Mestranda do Programa de Pós-Graduação em Educação - Curso Mestrado da Universidade Federal de Mato Grosso do Sul - UFMS. Especialista em Recursos Humanos e Graduada em Administração pelo Instituto Campo Grande de Ensino Superior. E-mail: lilianedesouzaa@gmail.com

${ }^{2}$ Como conceito realista a classe dominante, que designa uma população verdadeiramente real e detentores dessa realidade tangível que se chama poder (Bourdieu, 2004).

${ }^{3} \mathrm{O}$ capital simbólico assegura formas de dominação, que envolvem dependência perante os que ele permite dominar (Bordieu, 2001).
} 